\title{
EN MI MERO MOLE: UNA LECTURA ANTROPOLÓGICA de “Mole” en Chapters of Food
}

\author{
EN Mi MERO MOLE: AN ANTHRopological ReVieW \\ OF THE Video “MOLE” in Chapters of FoOd
}

\author{
María del Carmen Castillo Cisneros* \\ DOI: https://doi.org/10.31644/ED.V8.N1.2021.A07
}

\begin{abstract}
Resumen: En el capítulo "Mole" de Nowness, Chapters of Food, Enrique Olvera, un chef mexicano "de moda", afirma que el mole sabe a mole, no a la suma de sus ingredientes, ya que cuando los reúnes, todos renuncian a sí mismos. El mole, si bien es mole, lo es justamente porque todos sus ingredientes cooperan dando sabor y porque basta sumergir la yema de un dedo en la mezcla para reparar en cada uno de ellos. Decir que el mole sabe a mole es abstraer la complejidad de sus sabores y ello incluye los sabores culturales que su confección envuelve. En Oaxaca, los moles forman parte crucial de la cultura alimentaria de sus pueblos y cada uno posee una configuración particular que rebasa lo culinario. Por tanto, un mole es la condensación de múltiples relaciones sociales que coexisten más allá de folclorismos que fetichizan, encantan y matan. En este texto, a partir de mi trabajo etnográfico de casi dos décadas en el estado de Oaxaca, proporciono una lectura antropológica del video "Mole", retomando la importancia de la comensalidad y lo textil en el estado para resaltar que un ambiguo tratamiento de contenidos socioculturales termina siendo nocivo para eso que llamamos "nuestro patrimonio cultural".
\end{abstract}

Palabras clave: Oaxaca, mole, patrimonio, pueblos indígenas, textiles tradicionales.

Abstract: In Chapters of Food, Enrique Olvera, a trendy Mexican chef, states that mole tastes like mole, not like the sum of its ingredients because when you mix them, they all renounce to their own flavors. The mole, although it is mole, is just that because all its ingredients cooperate with flavors and because it is enough to dip the fingertip in the mixture to notice each of them. To say that mole tastes like mole is to abstract the complexity of its flavors and that includes the cultural flavors that its confection involves. In Oaxaca, moles are a crucial part of the food culture of their people and each one has a particular configuration that goes beyond the culinary. Therefore, a mole is the condensation of multiple social relationships that coexist beyond folklorisms that

* Dra. en Antropología Social, profesora investigadora del Instituto Nacional de Antropología e Historia, Centro
Oaxaca. ORCiD: https://orcid.org/0000-0002-7184-1910. Correo-e: carmen castillo@inah.gob.mx.

Fecha de recepción: 11/08/2020. Fecha de aceptación: 10/11/2020. Fecha de publicación: 30/01/2021.

(cc) BY-NC-ND

EntreDiversidades. Revista de Ciencias Sociales y Humanidades, vol. 8, núm. 1 (16), enero-junio 2021. Páginas: 164 - 185 ISSN-e: 2007-7610. https://doi.org/10.31644/ED.V8.N1.2021.A07 
fetish, enchant and kill. In this text, based on my ethnographic work of almost two decades in Oaxaca, I provide an anthropological review of the "Mole" video, emphasizing the importance of commensality and textiles to highlight that an ambiguous treatment of sociocultural content ends up being harmful to what we call "our cultural heritage".

Keywords: Oaxaca, mole, heritage, indigenous peoples, traditional textiles.

\section{Introducción ${ }^{1}$}

El mole ${ }^{2}$ es un platillo emblema que nos identifica como "mexicanos". De ahí que, el dicho de que una persona es "tan mexicana como el mole" es una suerte de común denominador cuando queremos asegurar que alguien lleva el pasaporte mexicano bien puesto, aunque está por demás subrayar la variabilidad implícita en "lo mexicano". Pero, más allá de su rol en la cocina mexicana, el mole como "genérico" se eleva a un pastoso recurso de identidad nacional, y en ese sentido se echa mano de él como un medio discursivo que, dicho sea de paso, también ensalza.

“¿Para cuándo el mole?”, preguntan los que quieren saber si pronto habrá casamiento. O bien se sabe que "guajolote que sale del corral, termina en mole". Nunca digas "no comí mole" sin limpiarte los morritos; y valga afirmar por precaución que "entre dos cocineras, sale aguado el mole". Del mismo modo se dice "es ajonjolí de todos los moles" para reiterar que una persona está involucrada en todo y aparece por doquier, mientras aseguramos con un "me diste en mi mero mole" lo mucho que algo nos gusta. Razón, no menor, indica que "el que come mole no lo oculta”, dejando ver que se trata de una salsa que a todos nos va.

Recordemos como anécdota que el 1 de enero de 1923, el estridentismo, movimiento de vanguardia encabezado por Manuel Maples Arce, lanza en la ciudad de Puebla su segundo manifiesto donde insta a ser irreverentes y defender la vergüenza intelectual invitando a la posibilidad de un arte nuevo, en el que Charles Chaplin sea angular, representativo y democrático. Dicho manifiesto contempla varios puntos, concluyendo con la premisa de que a los que no estén (con nosotros) se los comerán los zopilotes y que ser estridentista es ser hombre. Previo a la firma de los manifestantes, entre signos de exclamación, sobresale la provocadora consigna: "Viva el mole de Guajolote", externando un profundo desdén hacia la ranciolatría ideológica (europeizada) de aquel tiempo (Manifiesto estridendista, 1923). Un editorial de 1897 titulado "La influencia del mole", firmado con el seudónimo "Guajolote", oscilaba también entre el amor nostálgico y el desprecio burgués (Pilcher, 2001: 116).

\footnotetext{
${ }^{1}$ Agradezco a Laura Vit y Maru Falomir por la minuciosa lectura y comentarios hechos al texto.

${ }^{2}$ Previo a la lectura, se recomienda ver el episodio señalado en el siguiente enlace: https://www.youtube.com/ watch?v=Q4WDmXh6CT0
}

EntreDiversidades. Revista de Ciencias Sociales y Humanidades, vol. 8, núm. 1 (16), enero-junio 2021. Páginas: 164 - 185 ISSN-e: 2007-7610. https://doi.org/10.31644/ED.V8.N1.2021.A07 


\section{Pero, ¿qué es el mole?}

Para Cristina Barros (2005: 20), gran estudiosa del tema, los moles o salsas tienen su origen en la cocina prehispánica y son la base de un buen número de platos fuertes de la cocina tradicional mexicana. Tienen, como ingrediente particular, diversos chiles frescos y secos que son su principal especia, a los que se les añade tomate o jitomate molidos. Existen tanto caldosos como espesos, condimentados con diferentes hierbas y aunado a ello, con el tiempo, han recibido especias de lejanas latitudes como complemento.

Jeffrey Pilcher, en su impecable articulación de la comida y la construcción de la identidad mexicana, señala que Fray Bernardino de Sahagún reportó que los indígenas preparaban el pavo con varias salsas diferentes que incluían chiles amarillos, verdes y rojos. Los chiles amarillos y los jitomates se usaban para preparar el pescado blanco y las aves, mientras que los pescados de piel oscura iban mejor con chiles bermejos y pepitas de calabaza molidas. Otro chile rojo, el chiltécpitl, se usaba para la salsa correcta de los camarones, y los chiles verdes representaban el condimento natural para las ranas (Pilcher, 2001: 40).

Por su parte, Eduardo Merlo (2017: 33) sostiene que existió un guiso ancestral que los hablantes del náhuatl llamaron chilmolli y que es, de acuerdo con el autor, el abuelo del mole. Se hace mención de él en el Huehuetlatolli, como parte de los consejos que les hacen a los niños para decirles que no hagan ruido jadeando cuando beban agua o tengan que comer chilmolli.

Sin profundizar en las características de tal chilmolli, básicamente se trataba de una pasta hecha de chiles molidos en metate combinados con maíz molido a la que posteriormente se le agregaban otros ingredientes al gusto o simplemente, con esa mezcla (de variado espesor), se mojaban las tortillas. Cabe destacar que molli y moler son palabras prácticamente iguales y que la palabra chilmolli se compone de las voces chilli, que alude al chile o capsicum, y molli o molonqui, que significa triturar, machacar o moler. Si la pasta era espesa se le llamaba chilatextli, si tenía cacahuate, chilcacáhuatl, y si era aguado, chilátl (Merlo, 2017).

En ocasiones la molienda se enriquecía con jitomates, tomates o miltomates, que agregaban acidez, al tiempo que restaban picor. Es así que la amplia variedad de chilmolli fue, en aquel entonces, tan variopinta como las versiones de mole (de distintas procedencias) que transitan a lo largo y ancho del ahora territorio mexicano. Como bien sabemos, en "Mesoamérica se desarrolló una innovadora cocina popular sobre la modesta base del maíz y los chiles” (Pilcher, 2001: 43), y donde hubo milpa y metates hubo chilmolli.

Sin embargo, "el chilmolli original fue sublimado por las monjas cocineras de Puebla de los Ángeles. Le ańadieron especias y condimentos de grasas y carnes, y resultó en el digno sucesor de nuestra salsa: el mole poblano que lentamente desplazó al chimolli, y que dio lugar a infinidad de moles, todos platillos de lujo y de fiesta como su antecesor" (Merlo, 2017: 39). De ahí que el mole contrajera su fama nacional como ícono de una cocina mestiza resignificada.

Es interesante acotar que, en una época de creación de nacionalismos, lo que ocurrió en Puebla catapultó el mole como platillo de mexicanidad; mientras en otras geografías nacionales no repercutió de la misma forma, haciendo que los posibles chilmolli sobrevivientes quedaran esperando turno.

EntreDiversidades. Revista de Ciencias Sociales y Humanidades, vol. 8, núm. 1 (16), enero-junio 2021. Páginas: 164 - 185 ISSN-e: 2007-7610. https://doi.org/10.31644/ED.V8.N1.2021.A07 
El virtual monopolio de las cocinas criollas se hace evidente en el tratamiento comparativo del mole. El principal rival de Puebla en la preparación de este plato, el estado meridional de Oaxaca, se conoce hoy como "la tierra de los siete moles". Sin embargo, los libros del siglo XIX ignoraban las versiones más indígenas del mole oaxaqueńo, como el verde, perfumado con la incomparable fragancia anisada de la hoja santa, y se concentraban más bien en el mole negro, similar a la legendaria preparación poblana (Pilcher, 2001: 87).

Oaxaca, a diferencia de Puebla, que se yergue como una ciudad criolla, se jacta de ser epicentro de lo "indígena” y hoy, más que nunca, el recurso de lo auténtico, lo original, las raíces y lo nativo forman parte de un discurso global y contemporáneo que es revisitado para reformular identidades, pero al mismo tiempo sirve como estrategia de mercantilización y patrimonialización de la cultura. Llegados a este punto donde la cultura es mercancía, el mole como artilugio monumental, vende.

Al respecto, Pilcher (2001: 87) afirma que la cuisine nacional decimonónica, al definir hasta los chiles en términos criollos, ignoraba una geografía gastronómica que se remontaba a la época prehispánica. A saber, las tradiciones culinarias nativas se centraron en torno a las civilizaciones como la maya, zapoteca, mixteca y totonaca; que otrora ignoradas, hoy son volteadas a ver como componente capital de una pertenencia que siempre ha vinculado el mundo de los vivos y el de los muertos. Acaso, ¿no es el mole el plato principal en un altar de muertos? El turno llegó entonces al estado más diverso del país que tenía bajo la manga tantos moles como ases y que el chef Olvera abanderó desde su cocina.

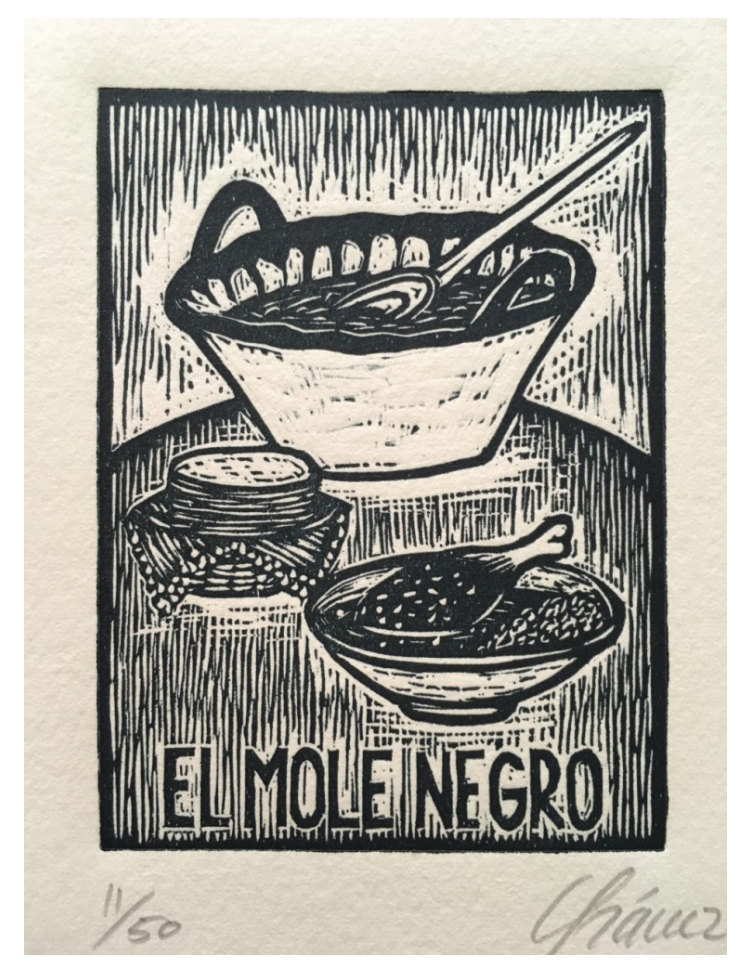

Mole negro. Grabado en linóleo. Edith Chávez, 2019.

EntreDiversidades. Revista de Ciencias Sociales y Humanidades, vol. 8, núm. 1 (16), enero-junio 2021. Páginas: 164 - 185 ISSN-e: 2007-7610. https://doi.org/10.31644/ED.V8.N1.2021.A07 


\section{El mole madre}

El "mole madre" no es más que un espejo de la época en que vivimos. Una versión contemporánea del mole negro oaxaqueño representado a partir de dos círculos que son la abstracción misma de nuestra historia. Un círculo de mole fresco coloradito al centro y otro rodeándolo, el negro, producto de un mole recalentado durante más de cinco años, lo que le da el título de madre. Ya menciona Georgina Cruz (comunicación personal), cocinera tradicional con más de cinco décadas de experiencia y hoy "mayora” del restaurante Hierba Dulce, ${ }^{3}$ que el mole coloradito y el negro son el mismo, solo que llevan diferentes chiles y por tanto el sabor se dispara.

De la misma manera que pasa con el pan y su muy aclamada "masa madre" (fermento vivo que hay que alimentar), el mole madre de la cocina de Pujol ${ }^{4}$ también está vivo y va recalentándose cotidianamente bajo un atento cuidado. Como plato icónico de aquel restaurante, el mole madre nace de las manos de dos oaxaqueños (Jorge León y Luis Arellano) que retoman la confección del platillo tradicional de sus fiestas, ofreciendo a Olvera algo que después se volvería un parteaguas (hito) en su cocina.

En el capítulo de Chapters of Food, que convoca esta reflexión, Olvera comienza diciendo que el mole sabe a mole y que para hacerlo sus ingredientes renuncian a ellos mismos. Si bien, la directora Bárbara Anastacio ${ }^{5}$ se inspira en el trabajo onírico del cineasta Luis Buñuel para hablar de la pasión por este complejo guiso desde una mirada artística, me permitiré señalar algunas observaciones que nacen del ámbito socio-cultural que me parece importante abordar a continuación.

Desde mi punto de vista, el mole, si bien es mole, lo es justamente por la reunión de todos sus ingredientes (diversos y con historia) y porque basta una probada para reparar en cada uno de ellos, de ahí su magia, de ahí que nos enloquezca. De ahí que, como buen vehículo de la memoria, el mole forme parte de las estructuras de sentido que legitiman historias culinarias plagadas de saberes y sabores. Por tanto, decir que el mole sabe a mole es abstraer su complejidad, sintetizar su historia, pasar de largo frente a uno de tantos íconos culturales imprescindibles en la definición de los marcadores identitarios de una nación. En este sentido, el mole no renuncia, "renuncia Olvera a presentar sus ingredientes históricos, simbólicos y relaciones que crearon primero el chilmolli y luego los diferentes moles" (Falomir, comunicación personal).

La cocina de nuestro país como nuestra identidad es multivocálica y enteramente social; entre sus ingredientes coexisten la experiencia, la memoria, los saberes y múltiples relaciones socioculturales que son materializadas. Si alguien ha asistido a una festividad o ritual en alguno de los pueblos originarios que conforman nuestra federación, habrá reparado desde el primer momento en el enorme despliegue que implica "cocinar para festejar"; mecanismo que va más allá de la cuidadosa mezcla de ingredientes, cantidades y técnicas. Como bien dijera Jean-Francois Revel, las cocinas regionales "no son producto del arte sino de la etnología" (Pilcher, 2001: 242),

\footnotetext{
${ }^{3}$ Restaurante ubicado en el centro de la ciudad de Oaxaca que promueve una cocina desindustrializada, a fuego lento y de mujeres. "Privilegia un sentimiento colaborativo y orgulloso de las tradiciones que reconocen en las mayoras, la figura máxima de autoridad en las cocinas" https://www.hierba-dulce.com/ (Hierba Dulce, 2019).

${ }^{4}$ Enrique Olvera abrió el restaurante Pujol en la ciudad de México en el año 2000. De acuerdo a su website "su cocina siempre está transformándose; abreva ideas de aquí y de allá, reinterpreta y evoluciona, pero tiene las raíces puestas en los ingredientes y las técnicas mexicanas de todos los tiempos" http://pujol.com.mx/ (Pujol, 2019).

${ }^{5}$ Directora y fotógrafa. Realizadora de varios episodios del proyecto Nowness, Culture in Motion.
}

EntreDiversidades. Revista de Ciencias Sociales y Humanidades, vol. 8, núm. 1 (16), enero-junio 2021. Páginas: 164 - 185 ISSN-e: 2007-7610. https://doi.org/10.31644/ED.V8.N1.2021.A07 
porque comprenden un conjunto fijo de recetas, el manejo de los recursos locales y demás factores culturales que permiten su existencia.

Graciela Ángeles, cuarta generación de productores de mezcal de Santa Catarina Minas, Oaxaca, explica algo muy interesante sobre la elaboración del mezcal conocido como "pechuga":

Así como surgieron los moles, surgieron los mezcales. A las órdenes religiosas les encantaba experimentar con el alcohol y muchos de los ingredientes que lleva el mezcal pechuga en su destilación, son los mismos que conforman los moles: arroz, pasas, canela, plátano, anís, almendras, además de la carne de guajolote. Particularmente, son los mismos que en el mole negro, a diferencia de que el mezcal no lleva chiles, ni orégano. En Puebla, para elaborar la variedad de este mezcal ocupan el pavo completo sin vísceras y sin cabeza, el cual rellenan con especias, como si se tratara de pavo de fin de año. Le introducen chiles, lo cierran y lo cuelgan del cuello dentro del destilador (comunicación personal).

El tema de los sabores en moles y mezcales es muy importante; de ahí la relevancia de un concepto que busca hacer entender al consumidor que cada región tiene su propia técnica para producir mezcal y que esa técnica sumada al terruño (tipo de suelo y variedades que ahí crecen) y la sazón que tiene cada productor, es lo que va a dar unas notas y un gusto particular a la bebida. Ese concepto es el de gusto histórico (Ángeles, comunicación personal) que, tanto en el mezcal como en cualquier otro elemento gastronómico, parte de emociones, experiencias, costumbres y cosmovisiones compartidas.

\section{El mole bajo la lupa antropológica}

Nací y crecí en la ciudad de Puebla, custodiada por los volcanes Popocatépetl, Iztacíhuatl y una Malinche que diariamente me recordaban periplos de mestizaje. Mi memoria olfativa y afectiva se tomaron de la mano en el momento mismo en que Lola me enredó como "taco" (así se envuelve a los neonatos en México) y me bajó a la cocina para preparar el atole prestablecido para que mi madre recuperara las fuerzas y produjera la leche necesaria para criarme. Bajo su brazo, asistí a la confección del insumo que haría brotar mi primer alimento; desde entonces, los fogones, Lola y yo creamos un vínculo, no solo culinario, sino de síntesis identitaria.

En esa misma cocina angelopolitana, rodeada de violetas, embarré mis pequeños dedos con la masa de maíz que se pegaba sobre la mesa de granito y, subida sobre una silla de metal forrada de vinilo blanco, mantuve infinitas veces la mirada fija ante el vaivén que se producía sobre el metate. Mi cercano horizonte era entonces una piedra alargada que aplastaba jitomates tatemados y chiles remojados, con los mismos brazos morenos que me arroparon. En ese cronotopo comencé, sin saberlo, mi oficio como antropóloga y fue Lola, sin proponérselo, mi gran maestra.

Masticados y en la boca recibí los sabores de México que incluyen también los del racismo, la desigualdad social y la diversidad cultural de un país culturalmente inmenso y fragmentado. Se intercalaron con el gusto de pipianes, gorditas rehogadas en manteca, rábanos con limón o

EntreDiversidades. Revista de Ciencias Sociales y Humanidades, vol. 8, núm. 1 (16), enero-junio 2021. Páginas: 164 - 185 ISSN-e: 2007-7610. https://doi.org/10.31644/ED.V8.N1.2021.A07 
simples tortillas salpicadas de sal recién levantadas del comal. ${ }^{6}$ Estas últimas llevaban impresas las huellas dactilares de la mujer que, durante muchos domingos alimentando mi estómago, sembró los cuestionamientos sobre los que se erige parte de mi labor etnográfica. Recientemente hago conciencia de ello, ubicada en una coordenada distante de la que me vio nacer, pero que me ha permitido hacer las pesquisas que unas veces aplacan mis preguntas y otras tantas las echan a andar: Oaxaca.

Escribo entonces, desde este único emplazamiento en el mundo donde puedes confeccionar un guiso que es verde, espeso y acidito, hecho con miltomate (tomates verdes de milpa), chiles soledad y chiles de agua locales, hierbas criollas y una aromática hierba santa tomada del traspatio (todo verde); servirlo en loza de barro, que también es verde, y estar dentro de un inmueble cuyo patio espejea tornasolados verdes que la cantera aporta. Este lugar es la capital del estado que cuenta con mayor diversidad biológica y cultural. Donde quince pueblos originarios ${ }^{7}$ conviven entre múltiples lenguas, vestimentas y ritualidades, pero donde también cada pueblo tiene una manera de alimentarse. Porque como dijera Contreras (Ortí, 2014), "pese a lo mucho que se habla de la homogenización alimentaria que ha traído la globalización, lo que me llama más la atención es, tal vez, lo contrario: la pluralidad de prácticas y de actitudes alimentarias que hay hoy día”. Solo por poner un ejemplo, en el estado de Oaxaca la tierra nos regala más de veinticinco especies endémicas de chiles, que crecen en Costas, Sierras y Valles, desafiando un territorio accidentado de vastas tonalidades, que después se vuelven "moles".

\section{Mapa de la diversidad cultural presente en Oaxaca}

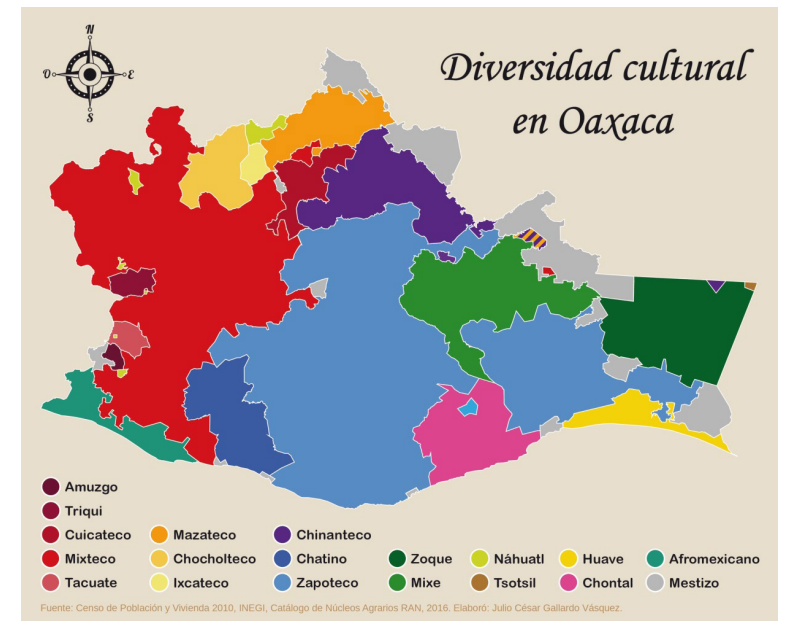

Fuente: Elaborado por Julio César Gallardo Vásquez, 2018.

\footnotetext{
${ }^{6}$ Utensilio de cocina, generalmente hecho de barro cocido, que se coloca directamente sobre el fogón.

${ }^{7}$ Oaxaca es el estado con mayor diversidad étnica de México. Los 15 pueblos originarios que lo habitan son: mazatecos, triquis, cuicatecos, zapotecos, mixtecos, mixes, chatinos, zoques, chinantecos, ixcatecos, amuzgos, huaves, chocoltecos, chontales y nahuas. Los tacuates pertenecen al grupo etnolingüístico mixteco pero se consideran una etnia diferenciada. Por otro lado, se cuenta con población tsotsil, afromexicana y mestiza no originarias, pero que suman a la diversidad cultural presente en el estado.
}

EntreDiversidades. Revista de Ciencias Sociales y Humanidades, vol. 8, núm. 1 (16), enero-junio 2021. Páginas: 164 - 185 ISSN-e: 2007-7610. https://doi.org/10.31644/ED.V8.N1.2021.A07 
Actualmente, la comida oaxaqueña es muy apreciada por propios y extraños, pero no siempre fue así, o no necesariamente lo es en cada uno de sus rincones. Si bien lo que comemos nos da identidad, en un país marcado por racismos, clasismos y discriminaciones la forma de alimentarnos también ha servido para polarizar a sus habitantes bajo el yugo de una ideología de Estado-nación, tantas veces perversa en términos de su pluriculturalidad. El fenómeno alimenticio es por ello socialmente complejo y candidato para ser analizado desde una perspectiva histórico-antropológica.

Siendo más concreta; en Oaxaca, donde conviven etnias distintas, sobreviven términos de raigambre colonial como lo son "gente de costumbre" y "gente de razón", categorías que continúan marcando las fronteras entre lo mestizo y lo indígena, $\mathrm{y}$, por consiguiente, hay comida y prácticas alimentarias asociadas a cada grupo. Lo cierto es que la construcción de estas ideologías continúa permeando prácticas y decisiones a bien entrado el siglo XXI y su reproducción; como recurso para responder a procesos de globalización y homogenización forman parte de "construcciones sociales del patrimonio alimentario" (Contreras y Ribas, 2014) que retornan a las fuentes culinarias "originales" para dar sentido a sus discursos.

Transitar vía terrestre la geografía de este estado es caer en una especie de ensoñación coloreada de distintos matices terrosos copeteados con montańas, órganos y cielos azules. Cada camino, cubierto de específicas mezclas minerales, es pisado al tiempo que maestros alfareros lo recolectan para lograr pigmentos que nos otorgan coloridas cerámicas. De ese mismo suelo brotan semillas, frutos y hierbas que metates, molcajetes y manos de molienda convierten en tintes naturales para teñir o que, unidos a otros insumos, forman moles; elaboradas mezclas comestibles que desde tiempos milenarios guardan, entre rocosos poros, el idilio de la fricción de cantos.

Yo, que creo en la alquimia y en las virtudes de los paladares que se dejan sorprender, creo en el mole como el resultado de un sueño venido de un desvelo, de un oasis en un desierto de sabores y sorpresas. Creo en el mole como la culminación del sincretismo que fundió dos culturas, provenientes ellas de otras más y que me hacen suspirar todos los días porque están en mi alma y en mi sangre (Taibo, 2005: 119).

Tenemos frente a nosotros tantos moles como chimollis hubo en la antigua Mesoamérica. Recetas que sobreviven trazando continuos culturales que parecen desafiar el tiempo. Los moles per se dotan de color, historia y sabor a las creaciones de quienes, en su hacer, parten de conocimientos específicos sobre mezclas, cocciones y tiempos precisos que han sobrevivido de boca en boca, de mano en mano. Como bien menciona Fischler (1995: 114), "ciertos alimentos, en todas las culturas, tienen una importancia peculiar, a la vez social e individual. Parecen comportar al mismo tiempo posturas colectivas y psicológicas. Parecen cargados de implicaciones sociales, así como de emociones, de poderosos afectos".

En un escenario diverso y peculiar como el oaxaqueño, estofados, coloraditos, amarillos, verdes, negros, manchamanteles y chichilos recrean, así, escenas de territorios diversos que van contándonos, en varias lenguas, relatos de bodas, nacimientos, fiestas y sucesos del ciclo de la vida cotidiana y ritual. Hablan de tácticas y técnicas específicas para preparar, servir, consumir

EntreDiversidades. Revista de Ciencias Sociales y Humanidades, vol. 8, núm. 1 (16), enero-junio 2021. Páginas: 164 - 185 ISSN-e: 2007-7610. https://doi.org/10.31644/ED.V8.N1.2021.A07 
y compartir. Son la abstracción de saberes que al recrear la monotonía también la rompen. Los moles son así, metáforas que cocineras y cocineros ponen en nuestras mesas. Alquimias cocinadas a distintos fuegos que son alegoría de nuestro picante territorio y el quehacer de sus habitantes. Son amalgama de negociaciones entre lo tradicional y lo moderno.

Es por ello que un plato como el mole lleva a cuestas conocimientos, recuerdos, tradiciones, sentimientos y emociones que hacen que sea algo más que un bocado que se lleva a la boca y se ingiera para alimentar y engordar cuerpos. Los moles son fiesta, alegría, dicha, celebración y luto. Los moles son pastas de afecto. "Degustar improbables ingredientes abre una ventana al porvenir, pero, sobre todo, remite al origen de los tiempos, cuando el apetito servía para descubrir la realidad" (Villoro, 2011).

Con cuarenta ańos, la empírica me aconseja y la etnografía me ancla, para afirmar que "el mole no sabe a mole" y que sostener tal enunciado solo confirma lo poco que nos conocemos en nuestras múltiples formas de ser mexicanos; aquel peligro latente con el que vivimos tan alejados de la realidad. De la misma manera, me indigna que en aquel capítulo ese platillo considerado "delicia terrenal" sea arrojado sobre una vestimenta que, cubriendo el cuerpo de una mujer con específicos diseños, significa. Si Enrique Olvera supiera que en el oficio de cocinar muchas mujeres voltean sus huipiles para no ensuciarlos, otra manera de relatar hubiera preferido. Unas que tampoco reunirían muxes, mariachis y diablos de la Costa en el mismo convite. Dicho revoltijo, si bien soy consciente que recae en un guion donde prima lo onírico, resulta un arma de doble filo que alimenta un folclor que mucho vende y poco aterrizaje tiene en escena. Ello fomenta la difusa idea de que con pisar Oaxaca uno tiene frente a sus ojos la Guelaguetza con su desfile de máscaras y danzas que reciben al foráneo al puro estilo de aloha Hawaii.

Si bien la alimentación cumple una función biológica al mismo tiempo que una función social esencial, nos enfrentamos ahora con una tercera función, la del "marketing cultural" (Hernández, 2018: 25). Y es ahí donde el concepto de patrimonio sale a relucir. Contreras y Ribas (2014), en su propuesta sobre la construcción social del patrimonio alimentario, retoman la definición de patrimonio dada por Prats (1997) que lo refiere como una construcción social que se fundamenta en los valores del tiempo (la idea del pasado), la naturaleza (espacio) y la genialidad o excepcionalidad (diferencia). Y la de patrimonialización de Frigolé (2008), como proceso de producción del patrimonio cultural o natural a partir de un conjunto de representaciones y prácticas que conforman estrategias e ideologías. Dicho de otra manera, esta capacidad de conferir valor a determinados bienes se puede identificar como el proceso de patrimonialización donde se activan recursos concretos, a menudo producto de la recuperación (Contreras y Ribas, 2014: 89).

Es un hecho que, en aras de asistir a la patrimonialización de la alimentación, voltear a ver el pasado en busca de productos recuperables que denoten tradición y originalidad ha sido la tónica. Por eso, el mole madre no es más que la resignificación de un alimento tradicional, que se hibridiza como producto de la invención de la tradición (Hobsbawm, 1989) y se pone a la venta.

Dicho esto, al mirar el video sobre el mole madre, es evidente que el arte no hace justicia, ya que no puede dejarse de lado la premisa de que "las prácticas alimentarias son prácticas relacionales" (Escobar, 2014) y que, por ende, su manejo implica una toma de responsabilidad sociocultural. De ahí que, a lo largo de estas páginas, haré mención de algunos aspectos (entre

EntreDiversidades. Revista de Ciencias Sociales y Humanidades, vol. 8, núm. 1 (16), enero-junio 2021. Páginas: 164 - 185 ISSN-e: 2007-7610. https://doi.org/10.31644/ED.V8.N1.2021.A07 
muchos posibles) en que baso mi resquemor y sobre los cuales gira una lectura antropológica basada en mi trabajo etnográfico con pueblos indígenas del estado de Oaxaca. Dicha lectura se hace desde la perspectiva de la comensalidad ritual y del mundo textil.

\section{Comensalidad: el encuentro del nomos y el cosmos en la mesa}

El vocablo comensalidad, literalmente, se refiere a compartir la mesa, y compartir la mesa lleva implícito repartir los alimentos. Mintz (2003: 28) no se equivoca al afirmar que "los alimentos que se comen tienen historias asociadas con el pasado de quienes los comen; las técnicas empleadas para encontrar, procesar, preparar, servir y consumir esos alimentos varían culturalmente [...] su consumo siempre está condicionado por el significado".

Como sabemos, cada sociedad humana es creadora de mundos y en cada uno de ellos figura la presencia de un nomos y un cosmos como elementos que coexisten. El primero, entendido como el orden socialmente establecido de las cosas, las normas, lo que está dado por una cultura. El segundo, como aquello que trasciende al hombre, un orden sagrado que legitima el primero (Castillo, 2014: 319). En Oaxaca coexisten una pluralidad de nomos y cosmos que pautan el quehacer cotidiano al interior de cada localidad del estado y sobre los que se erige la vida ordinaria y extraordinaria, lo sagrado y lo profano, el orden y el caos.

Los alimentos son portadores de sentido, y este sentido les permite ejercer efectos simbólicos y reales, individuales y sociales. El tomate y el caviar, de manera muy diferente, nutren ambos tanto a lo imaginario como al cuerpo. Permiten «construir» y poner en escena la realidad y las relaciones sociales. Se utilizan según representaciones y usos que son compartidos por los miembros de una clase, de un grupo, de una cultura. La naturaleza de la ocasión, la calidad y el número de los comensales, el tipo de ritual que rodea el consumo constituyen elementos a la vez necesarios, significantes y significativos. Los alimentos se combinan en comidas u ocasiones de consumo que, a su vez, permiten estructurar las situaciones y el tiempo: así, por ejemplo, el desayuno, un piscolabis, una "pausa café» (fórmula lanzada hace tiempo por una hábil campaña publicitaria) miden rítmicamente el tiempo laboral, contribuyen a ordenarlo y a ritualizar nuestras relaciones con él (Fischler 1995: 80).

La cocina, los saberes culinarios y su posterior comensalidad, como parte fundamental de todas las sociedades humanas, congregan ambas presencias. Por consiguiente, no se puede hacer alusión a ellas y sus componentes sin el escrutinio y rigurosidad que implica hablar de los patrimonios culturales tradicionales (donde nomos y cosmos conviven).

Como ejemplo, los ayuujk o mixes de Tlahuitoltepec, Oaxaca, cada $1^{\circ}$ de agosto comen un platillo llamado määtsy (machucado, traducido al castellano) para honrar al "señor hambre". Para su elaboración, se preparan varias memelas (hechas de masa de maíz mezclada con frijol y aplanadas) que se ponen en el comal y, antes de estar cocidas por completo, se sacan y se destruyen con las manos o se pasan por el metate, sin importar lo caliente que esté la masa. Lo resultante se amasa de nuevo y con ello se hace una bola que se coloca en una olla de barro de una sola asa, previamente

EntreDiversidades. Revista de Ciencias Sociales y Humanidades, vol. 8, núm. 1 (16), enero-junio 2021. Páginas: 164 - 185 ISSN-e: 2007-7610. https://doi.org/10.31644/ED.V8.N1.2021.A07 
ardiendo al fuego y asentada en el suelo. Inmediatamente después se añade a esta bola una salsa hecha de chiles y jitomate, o chiles y semilla de calabaza molidos, que baña toda la pelota y que con el calor de la olla comienza a burbujear. Todos se sientan en el suelo alrededor del recipiente.

El machucado siempre se come en colectivo y con las manos. Se acompaña con quelites (genérico utilizado para variantes de hierbas verdes comestibles) cocidos, carne o pescado seco y asado y chilacayotas cocidas. Además de ser una comida característica de ese día, el määtsy constituye la comida final o de cierre de cualquier ritual llevado a cabo por los mixes de Tlahuitoltepec. Este alimento recibe su nombre de la sustantivación del verbo mä̈äts que significa juntar, revolver o apachurrar. La gente de Ayutla cuenta que un señor se disfrazaba de "hambre" (vestido de harapos) y recorría caminos y veredas cada $1^{\circ}$ de agosto. El que lo encontraba debía invitarlo a comer y así se evitaría que el hambre entrara a la casa durante todo el año.

En su versión cierre de ritual, celebración o festividad representa una forma de disfrute comunal producto del trabajo participativo que se siguió. Sentarse en el suelo alrededor de esta comida es comer un cerro humeante que derrama lava; una metáfora comestible. Si bien los cerros representan el axis mundi para este pueblo, cuyo Zempoaltépetl (cerro de veinte picos) es el recinto de casi toda conmemoración ritual, no sería extraño que poner el machucado en el centro de la casa y participar todos de él sea un signo de comensalidad con el territorio que recuerda el vínculo sagrado con la tierra y todas las entidades que moran en ella (Castillo, 2014).

Tristemente y aun cuando he gozado sus mieles, coincido con Fischler (2010) cuando dice que la gran cocina, la de los chefs, ha sido elevada al rango de las bellas artes y esa elevación, por supuesto, ha traído consigo movimientos en el tablero de lo cultural. Los cocineros son rockstars y sus creaciones, como las de los grandes modistos, se exhiben, se exportan de un extremo a otro del planeta, son recuperadas, imitadas y caricaturizadas por los industriales o los artesanos del nuevo prêt-à-porter culinario. Hay en circulación una nueva estética y propuesta culinaria que se difunde bajo el credo de restablecer la verdad (en su acepción de originalidad y autenticidad) de los productos utilizados.

Aunque algunos han puesto en alto las diferentes cocinas de México atendiendo un gran número de flancos posibles, para otros pareciera que el tema recae en lo puramente gastronómico, mediático y turístico sobre lo que hay que enfocarse para vender. "Con base en estas situaciones se observa un desplazamiento de la cocina hacia la gastronomía como modelo científico, político y mercantil que inscribe la cocina en la veta de modernidad en vez de la tradición, lo que conlleva hacia una tendencia que mercantiliza a las cocinas tradicionales" (Hernández, 2018: 23).

Bajo esta retórica, Oaxaca ha encajado como anillo al dedo cuando de trazar continuidades culturales, que guiñan el ojo con autenticidades, originalidades y sabores ancestrales, se trata. De pronto, este punto en la cartografía de América, se vuelve el ombligo moderno de Mesoamérica que legitima una ancestralidad que hoy más que nunca es la fórmula secreta que todos quieren compartir en la mesa. El origen del maíz, el mezcal... el mole verdadero. Si bien, todo ello cuenta con una gran importancia histórica, su valía a nivel mercantil ha destapado una gran olla en la que pareciera necesario zambullirse para continuar.

EntreDiversidades. Revista de Ciencias Sociales y Humanidades, vol. 8, núm. 1 (16), enero-junio 2021. Páginas: 164 - 185 ISSN-e: 2007-7610. https://doi.org/10.31644/ED.V8.N1.2021.A07 
En este tenor, Enrique Olvera tal vez no sabía lo que buscaba, pero queda claro que algo buscaba cuando le pidió a Jorge León ${ }^{8}$ (Restaurante Alfonsina) y Luis Arellano (Restaurante Origen), en aquel entonces dos oaxaqueños recién enfilados en las cocinas de Pujol, que echaran a volar su creatividad y le presentaran algo característico de su estado, pero re-conceptualizado; en otras palabras, una creación gestada desde "la tradición". Encendiendo los fogones de su memoria y dando uso a unos chiles almacenados que custodiaba el chef Ricardo Muñoz Zurita, Jorge cuenta que él y Luisito aterrizaron en la confección de un mole a la usanza de las fiestas de los Valles Centrales en Oaxaca.

El mole, cuando festivo, suele pensarse en grandes cantidades. En las comunidades eso forma parte de una compleja labor que requiere de la guía de una mayora o wendau del pueblo, cuyo trabajo consiste en establecer ingredientes, cantidades, procesamientos y coordinación de muchas manos que recrean tradiciones culinarias compartidas por una cultura. En este despliegue de preparativos y víspera están siempre presentes un nomos y un cosmos que sin ser tangibles se compartirán entre los comensales. Fue en ese "hacer" y "ser" del mole, confeccionado por muchas manos en eficiente división de trabajo, en el que se inspiraron Jorge y Luis. Aquel que resultaría en el aclamado "mole madre" de Pujol.

En términos rituales, en Oaxaca, la comida constituye el componente central de una fiesta y cada una de ellas reproduce elementos que para una cultura significan. De la comida y sus usos se infiere un interesante ingenio social que, bajo aromas y sabores, esconde mecanismos de continuidad de saberes que nos enorgullecen (en tanto símbolos culturales) y que venimos reproduciendo desde épocas milenarias, pero también de cosas no tan positivas como explotación, maltrato, desigualdad y discriminación normalizadas y heredadas.

Para poner en contexto, las mayordomías, que son celebraciones de los santos y fechas del calendario de la Iglesia católica, implican despliegues festivos de inmensa producción. Ser mayordomo o capitán de festejo es tomar un cargo comunitario que consiste, a grandes rasgos, en patrocinar una fiesta y agasajar con ello a familiares, amigos, vecinos y demás miembros de la comunidad. Las mayordomías requieren la participación de mucha gente y habilidades varias para cumplir con los mecanismos rituales y la preparación de comida en abundancia. Debido a esto, un mayordomo nunca está solo y con anticipación invita a "su gente" en busca de trabajo y ayuda que posteriormente reciprocará. Por tanto, las mayordomías son celebraciones que requieren mucho dinero y donde no solamente se alimentan personas, sino también relaciones sociales de intercambio, ayuda mutua, compadrazgo y distintos mecanismos comunitarios que representan sacrificio y dan prestigio.

\footnotetext{
${ }^{8}$ Entrevista realizada en febrero de 2019. Jorge León, apodado "el moles" en la cocina del Restaurante Pujol, es originario de Santo Domingo Nundó, mixteca oaxaqueńa y actualmente vive en San Juan Bautista La Raya donde recién inició el proyecto de Alfonsina. Jorge se inició en la cocina de Casa Oaxaca como lavalozas y continuó su carrera como cocinero impulsado por Alejandro Ruiz quien luego lo empujó a trabajar en Pujol donde colaboró los últimos seis ańos. Por su parte, Luis Arellano dirige el Restaurante Origen también establecido en la ciudad de Oaxaca.

${ }^{9}$ Nombres con los que se designa a cocineras consagradas en su oficio, que no solamente dominan la sazón, sino los cálculos necesarios para alimentar a grandes contingentes. El término wendau pertenece a la variante zapoteca de San Francisco Cajonos, Oaxaca.
}

EntreDiversidades. Revista de Ciencias Sociales y Humanidades, vol. 8, núm. 1 (16), enero-junio 2021. Páginas: 164 - 185 ISSN-e: 2007-7610. https://doi.org/10.31644/ED.V8.N1.2021.A07 
En muchas mayordomías, a la par que se preparan los platillos que serán consumidos por los humanos, deben elaborarse platillos dedicados a entidades que pueblan el cosmos (muertos, deidades míticas, santos católicos o potencias atmosféricas). Los altares de muertos constituyen el ejemplo más conocido, pero no el único. Alrededor de la geografía oaxaqueña, una serie de montañas, cerros, honduras, ríos o cuevas, considerados lugares sagrados donde moran entidades extrahumanas, son constantemente visitados y ofrendados en diferentes momentos del ciclo anual, sea para mayordomías u otros rituales del ciclo agrario y del ciclo de la vida. La comida, así, traspasa las fronteras cotidianas de subsistencia para jugar un papel central en la vida religiosa y ceremonial de los pueblos y es algo completamente vivo y en constante reactualización.

Preparaciones singulares de moles, caldos, tamales y guisos variopintos dejan ver las distintas épocas del año, la relación con el entorno biológico, los productos locales y la búsqueda de otros que son considerados suntuosos y escasos. Mientras tanto, en las cocinas, las manos, generalmente femeninas, se multiplican y entretejen coordinadamente para la confección masiva de alimentos cuyo fin último es el convivio colectivo con las diferentes entidades que pueblan el mundo. En Tlahuitoltepec, de la misma manera en que se observa una compleja producción fordiana para elaborar tamales para los humanos se ve otra para elaborar figuras contadas de masa de maíz que servirán de ofrenda en el cerro sagrado. Igualmente, en Santa Cruz Mitlatongo canastas llenas de enfrijoladas, carne de chivo y pinole ${ }^{10}$ se ofrendan al interior de las Casas de la lluvia distribuidas a lo largo del territorio mixteco.

Como alguna vez me contara una mujer ayuujk (mixe), por la noche se debe voltear el metate para que duerma, ya que es considerado una "persona" porque trabaja y se alimenta. Por ello, se dice que, en agradecimiento a ese alimento diario que se le da, el día del fin del mundo es el único utensilio que va a llorar por los humanos, a diferencia de ollas y comales que perseguirán a las personas para quemarlas haciéndolas pagar por el daño recibido.

La riqueza del contexto festivo oaxaqueño no responde al azar, mantiene un estricto orden y una estructura que cada configuración cultural respeta y conoce. Un mole de boda es la culminación de una serie de pedimentos, visitas constantes de los familiares del novio a los familiares de la novia, acuerdos, regalos, dotes establecidas y negociaciones cabalmente cumplidas entre personas de la comunidad, difuntos a los que se visita en el panteón y otras entidades a las cuales debe notificarse de la unión. Eso, más la elaboración de las comidas pertinentes que exigen las potencias extrahumanas, son parte del ciclo ritual de muchos pueblos indígenas del estado. Por ello, un festejo no es solo un festejo.

En lengua ayuujk o mixe, un ritual pretende tyik pijyi tyik xuukyi, hacer florear, hacer perfumar. Tyik es movimiento, pijyi, flor y xuukyi es oler o lo que huele (lo que perfuma). Por tanto, tal como sugerimos en otra investigación, todos los alimentos (los destinados a los dioses y los destinados a las personas) deben tener esa característica de mover, perfumar, dar aroma como las flores. Se dice que la familia que da la fiesta está haciendo florear, está haciendo perfumar una fiesta, por lo tanto, todos los elementos rituales están en función de eso (Castillo, 2013a: 13).

En Oaxaca es evidente que la cocina no solamente incluye buenas recetas y sabores; también coloca contextos sociales sobre la mesa. En este sentido, hablar de ella y ponerla bajo reflectores

${ }^{10}$ Harina de maíz endulzada con piloncillo o panela (endulzante obtenido del jugo sin destilar de caña de azúcar).

EntreDiversidades. Revista de Ciencias Sociales y Humanidades, vol. 8, núm. 1 (16), enero-junio 2021. Páginas: 164 - 185 ISSN-e: 2007-7610. https://doi.org/10.31644/ED.V8.N1.2021.A07 
debe proporcionar una imagen lo más apegada a la realidad de nuestro país y sus diversos pobladores. Si el alimento, como bien asegura Douglas (1972), es un código, su práctica, su teoría y su difusión deben partir de los múltiples conocimientos y memorias culturales que existen.

Sin lugar a dudas, las cocinas son una gran herramienta de investigación social para conocer diferentes historias que implican diversas dimensiones del ser. Permiten conocer una amplia gama de realidades que se dan a partir de la alimentación y que son sustento de las diferentes culturas. En consecuencia, la comensalidad (entre distintas entidades), ese compartir entendido como comer y beber juntos alrededor de la misma mesa, trata también de conversaciones, rińas, anécdotas o simples actos gestuales que envuelven las maneras de entender el mundo, estructurarlo y habitarlo. Experiencias que acompañan lo culinario y que, de bocado en bocado, se saborean y mastican reforzando una cultura.

En ese sentido, la cocina es un vehículo de sociabilización, no solo de personas, sabores e insumos; sino de formas de pensar y ordenar el mundo, de reglamentar lo que es permitido y lo que no lo es y de estructurar lo que es bueno para comer o malo en una cultura determinada.

Comer es pensar. En su relación con el mundo, consigo mismo, con los demás individuos y la colectividad, hemos visto que el omnívoro humano tiene una necesidad constante de pensar su alimentación, de razonarla o de racionalizarla. Examinando la relación del hombre con sus alimentos, no hemos dejado de encontrar nociones de orden y de organización, de coherencia, de regulación. Las razones son probablemente biológicas, cognitivas, sociales (Fischler, 1995: 371).

Por tanto, coincido con Escobar (2014: 16) cuando afirma que la "cocina gourmet" individualiza en tanto crea experiencias para personas con gustos refinados, experiencias que comienzan y terminan en el acto mismo de alimentarse, mientras que la cocina tradicional apela a la sociabilidad y mantenimiento de un lazo social entre cocinero y comensal a través de la comida. De esta manera, el saber/sabor de la cocina tradicional dota de historia, afecto y subjetividad a la comida, y el comensal, por su parte, recibe en su cuerpo toda la carga simbólica de un habitus.

Con todo ello sobre la mesa, no quiero decir que el chef Olvera carezca de conocimiento ni que en su día a día dichas premisas sean pasadas por alto. Por el contrario, creo que su trayectoria, sus proyectos y la gente que trabaja con él pueden argumentar la importancia que lo sociocultural tiene en su cocina. Sin embargo, el video, desacertadamente, nos muestra un habitus maquillado y descontextualizado que poco tiene que ver con las formas en que los oaxaqueños (siendo genéricos) interiorizan lo social o estructuran sus prácticas culturales de acuerdo a esa comensalidad dada entre sus nomos y sus cosmos.

Quiero subrayar que aplaudo el interés que la cocina gourmet presta en conocer distintas realidades culturales para dar cuenta de la existencia de extendidos patrones alimentarios tradicionales. Pero, recalco que hacerlo implica una responsabilidad histórica y social que debe ir de la mano de la memoria y oralidad de sus protagonistas para dar una imagen más apegada a la realidad.

Dicho lo anterior, desde mi óptica, ni Anastacio como directora, ni Olvera como intérprete, repararon en ello. De tal suerte que abren la puerta a una lectura fantástica y exótica de lo 
"tradicional" que reafirma falsas ideas del buen salvaje, su primitivismo y otras concesiones ficticias dadas a la imagen del "otro". Una vez más se trata de herramientas al servicio de la mercantilización de patrimonios ancestrales y no de elementos que permitan una comensalidad de conocimientos sobre la pluralidad cultural existente en nuestro país.

\section{Mujeres mixtecas de San Pablo Tijaltepec}

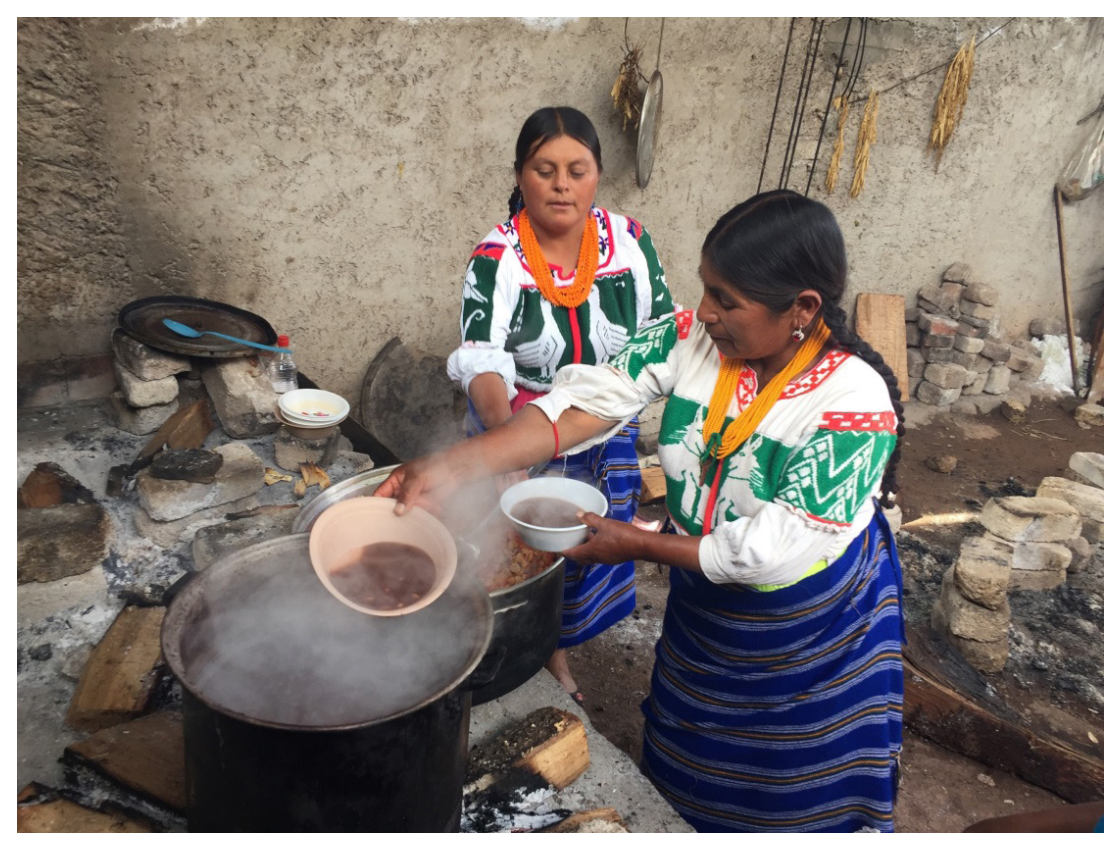

Fuente: María del Carmen Castillo Cisneros, 2018.

\section{Tejer como cocinar}

Se me ocurren una decena de platillos oaxaqueños, más allá de sus moles, que incluyen una retahíla de sabores complejos que estas tierras obsequian a manos llenas. Pero entiendo bien que el mole es ese platillo que nos hace suspirar. Taibo (2005: 119) asegura que explicar un mole, según se vea y dependiendo de la esquina del ring en la que uno se encuentre, puede ser una tarea divina o diabólica y Villoro (2015: 12), al afirmar que los platillos mexicanos cultivan el sabroso malentendido y el arte de comunicar mucho sin revelar todos los secretos, menciona en primera línea al mole, como aquel que incluye fruta y chocolate y no es dulce, siguiendo con el uso de la pepita de calabaza para neutralizar el chile usado en el pipián. ${ }^{11}$

Cuando uno recorre el mercado de Tlacolula, se llena de color. Frutas, verduras, panes de todos los tamaños, trozos de carne secándose, especias, chiles, semillas y por supuesto mascadas floreadas atadas a la cabeza, como acostumbran a llevar las mujeres de San Bartolomé Quialana, o mandiles bordados que cubren los vestidos de marchantas y visitantes que bajan de los pueblos aledaños.

\footnotetext{
${ }^{11}$ El pipián es otra pasta (como el mole) elaborada principalmente con pepitas de calabaza y chiles. Hay pipianes verdes y rojos, cuya tonalidad depende del color de los insumos utilizados.
}

EntreDiversidades. Revista de Ciencias Sociales y Humanidades, vol. 8, núm. 1 (16), enero-junio 2021. Páginas: 164 - 185 ISSN-e: 2007-7610. https://doi.org/10.31644/ED.V8.N1.2021.A07 
Pienso ahora en clave textil. En las artesanas de San Juan Colorado metiendo madejas de hilos a ollas que burbujean tinturas de hoja de guayaba que les recuerda un guiso costeño. La hoja es verde, pero tiñe rojito, me comentan cuando pregunto por los tintes naturales. Me siguen impactando las manos sobre metates que coloreadas hasta la dermis permanecen violáceas o magentas moliendo grana cochinilla o añiles para pigmentar lienzos. A pesar de mi familiaridad con el mundo textil, no dejo de sorprenderme al observar anversos y reversos de un lienzo que muestran, al estilo fotográfico, detalladas puntadas en positivos y negativos de la misma historia. Tantos otros, muestran un anverso legible y un reverso tan discontinuo que borra los trazos del relato contado de frente.

Los textiles mexicanos, al igual que los platillos, se cultivan, se preparan y se cocinan entre tramas y urdimbres que dan cuenta de memorias bioculturales expresando los "malentendidos" —como bien dijera Villoro (2015: 12) — que saben mientras comunican algo.

Camino a la costa oaxaqueña, en las inmediaciones de un paraje cuyas venas transportan río arriba aguas cálidas que desembocan en una poza de agua caliente y cuyos pobladores me alimentaron con atole de camote de huichicata (malanga), gajos de yaca, ácidos marańones y tortillas de maíz nuevo, pasé recientemente unos días observando el transitar de la vida tacuate. Entre atarrayas bien tejidas pescan potes, charales, camarón burro, mojarras y cangrejos. Estos últimos, bordados también en sus huipiles, acompañan a una serie de animalitos que a la vez que están presentes en la vida diaria del campo, juegan un papel importante dentro del chamanismo y nagualismo que los tacuates comparten.

En este lugar, como en la mayoría del mapa oaxaqueño, textiles y comidas son relatos que cuentan y significan. Unos están escritos con ingredientes locales, los otros redactados en telares, con hilos y agujas. Ambos otorgan el sabor de la tierra; los resabios del metate donde se han molido chiles y tintes para obtener pastas de color. Ambos transitan de ida y vuelta a tiempos pasados y se incorporan en la vida del hoy. Platillos e indumentarias se resignifican para existir, otorgando siempre identidad.

Que no se nos olvide que en aquello que una vez se denominó Mesoamérica seguimos vistiendo o tapando todo aquello que nos importa. No solo lo hacemos con cuerpos; vestimos tortillas, tapamos el pan, amortajamos a nuestros muertos, adornamos cruces, envolvemos tamales con diversas hojas o cubrimos ollas con servilletas tejidas que contienen los alimentos que queremos guardar del sereno. Si alimentos y textiles son aliados de nuestras corporalidades, me pregunto, ¿por qué habría de mancharse indiscretamente una prenda con mole? ¿Por qué colocar ambas creaciones socioculturales en disputa?

Los textiles y las comidas tradicionales van más allá de su funcionalidad como objetos, se trata de objetos-sujetos culturales que mantienen significativas relaciones sociales, y en Oaxaca, cocinas y textiles, moles y huipiles deben por ello entenderse desde un enfoque relacional y desde una lógica de labor que parte de la memoria biocultural existente. Boege lo explica de la siguiente manera:

Los pueblos indígenas crean y recrean sus culturas en espacios geolocalizados, se organizan en sus tierras, comunidades agrarias, territorios y/o regiones determinadas y tienen una fuerte vinculación con el uso milenario de los recursos naturales y biológicos que conforman ensambles ecosistémicos

EntreDiversidades. Revista de Ciencias Sociales y Humanidades, vol. 8, núm. 1 (16), enero-junio 2021. Páginas: 164 - 185 ISSN-e: 2007-7610. https://doi.org/10.31644/ED.V8.N1.2021.A07 
y paisajes. Íntimamente ligados están los sistemas alimentarios locales que determinan una cultura culinaria, así como otros aspectos relacionados con la vestimenta, la salud, los conocimientos y los imaginarios socioambientales, organizados por la cosmovisión (Boege, 2017: 43).

Atendiendo el contexto de los pueblos oaxaqueños donde he realizado mi trabajo etnográfico, jamás alguien ensuciaría intencionalmente un huipil, un enredo, una blusa o cualquier prenda que forme parte de la indumentaria. De hecho, en Zacatepec, Putla, donde el Carnaval se celebra con todo lujo de caos y desorden y la gente sale a las calles para pintar a otros con tizne, pintura de aceite o reventar huevos en cabeza ajena, a diferencia de la población mestiza, para quienes no parece importar el hecho de ensuciar la ropa y de antemano se ponen disfraces o prendas viejas, para los tacuates significa un problema.

Por esa razón, sobretodo las mujeres, prefieren no salir, con la excusa de que los participantes "hacen feo" y manchan o, en caso de animarse a transitar las calles, generalmente utilizan huipiles muy viejos que voltean o visten aquellos hechos de telas sintéticas o desgastados para posteriormente darlos de baja quemándolos. Porque sí, igual que los residuos de basura orgánica, los huipiles, en algunas comunidades indígenas, se queman y eso también forma parte de particulares creencias que se relacionan con el inframundo y sus habitantes.

Siguiendo con el ejemplo anterior, agrego que uno de los principales motivos por los que la comparsa de "las mascaritas" (tacuates vestidos de hombres y mujeres a la usanza tradicional) toma un rumbo diferente en el recorrido del pueblo durante el Carnaval tiene que ver con el temor a que sus huipiles y cotones sean manchados.

Nunca antes me había detenido en esta observación, toda vez que el carnaval sugiere aristas más coloridas por donde mirar. No obstante, este dato etnográfico, aunado a la pesquisa en términos de cosmovisión y significados que cada textil detenta, ${ }^{12}$ me sirve para sustentar que aquella escena del video donde se le arroja mole a una chica que viste un huipil blanco, independientemente de la posible defensa artística que pueda tener desde el punto de vista cinematográfico, constituye una falta de respeto y, por tanto, de conocimiento ante dos manifestaciones culturales que en Oaxaca son marcadores de historia y continuidad: la indumentaria y la culinaria tradicional.

Recurro a un relato recogido por Acosta para ejemplificar la relación medular que existe en algunas (si no todas) culturas entre vestimenta y alimento como parte de la cosmovisión compartida:

Se sabe que al interior del cerro Boludo o de la mujer, ubicado en Atla, una comunidad de la Sierra Norte de Puebla, vive la Sowapili o entidad femenina considerada potencia tutelar de las parteras y del bordado, y que se encuentra vestida con la indumentaria tradicional que usaban las mujeres antiguas. De ese cerro, se dice que nacen los hilos para bordar y es parte de la ritualidad, ofrecer el primer bordado que hace una nińa a dicha deidad. De la misma manera, en este mismo cerro, los tetlachihke y los tlamatkime (brujos y adivinos) acuden para llevar a cabo "el costumbre" o tlachiwake y se cuenta que al interior se encuentran brujas difuntas haciendo

${ }^{12}$ Desde 2015 he trabajado el tema textil en el estado de Oaxaca, principalmente los casos de plagio. Realicé el dictamen de la blusa de Tlahuitoltepec y a partir de enero de 2019 dirijo el proyecto de investigación "Memoria textil", que atiende distintas demandas comunitarias en relación a los textiles tradicionales al mismo tiempo que registra historias étnicas relacionadas con la indumentaria.

EntreDiversidades. Revista de Ciencias Sociales y Humanidades, vol. 8, núm. 1 (16), enero-junio 2021. Páginas: 164 - 185 ISSN-e: 2007-7610. https://doi.org/10.31644/ED.V8.N1.2021.A07 
tortillas y bordando. La Sowapili sostiene el mundo y lo mantiene a partir del bordado, por tanto, si el fin del mundo no ha llegado, es porque ella tiene muchos hijos, mucho hilo y mucho trabajo. En pocas palabras la Sowapili con su hilo para bordar sostiene y alimenta al mundo (Acosta, 2018: 122).

Reparar en estos contenidos repercute en la manera en que pensamos y consecuentemente contamos las cosas. Si bien una escena puede ser leída de muy distintas maneras, pensar que su correcta lectura parte de una sola lógica de pensamiento es peligroso y reproduce la prevalencia de saberes hegemónicos que lejos de promover diálogos interculturales imponen monólogos sobre los ámbitos no occidentales.

He recopilado relatos sobre textiles entre los mixes, los tacuates, mixtecos de la Costa y zapotecos de los Valles. La importancia de todas estas narrativas que apelan a la memoria y se relacionan con distintos elementos culturales yace en la utilización de las mismas como recursos útiles para la creación de sentido. Sueños, monolitos grabados, cuentos, personajes míticos, acciones de potencias extrahumanas o conocimientos chamánicos alimentan los diseños que, por años, se han reproducido mediante tejidos y bordados tradicionales. Esos sentidos cimientan las distintas culturas que coexisten en nuestro país y constituyen, en mi opinión, los patrimonios culturales que no debemos pasar por alto porque, ante todo, tienen historia, nombres y apellidos.

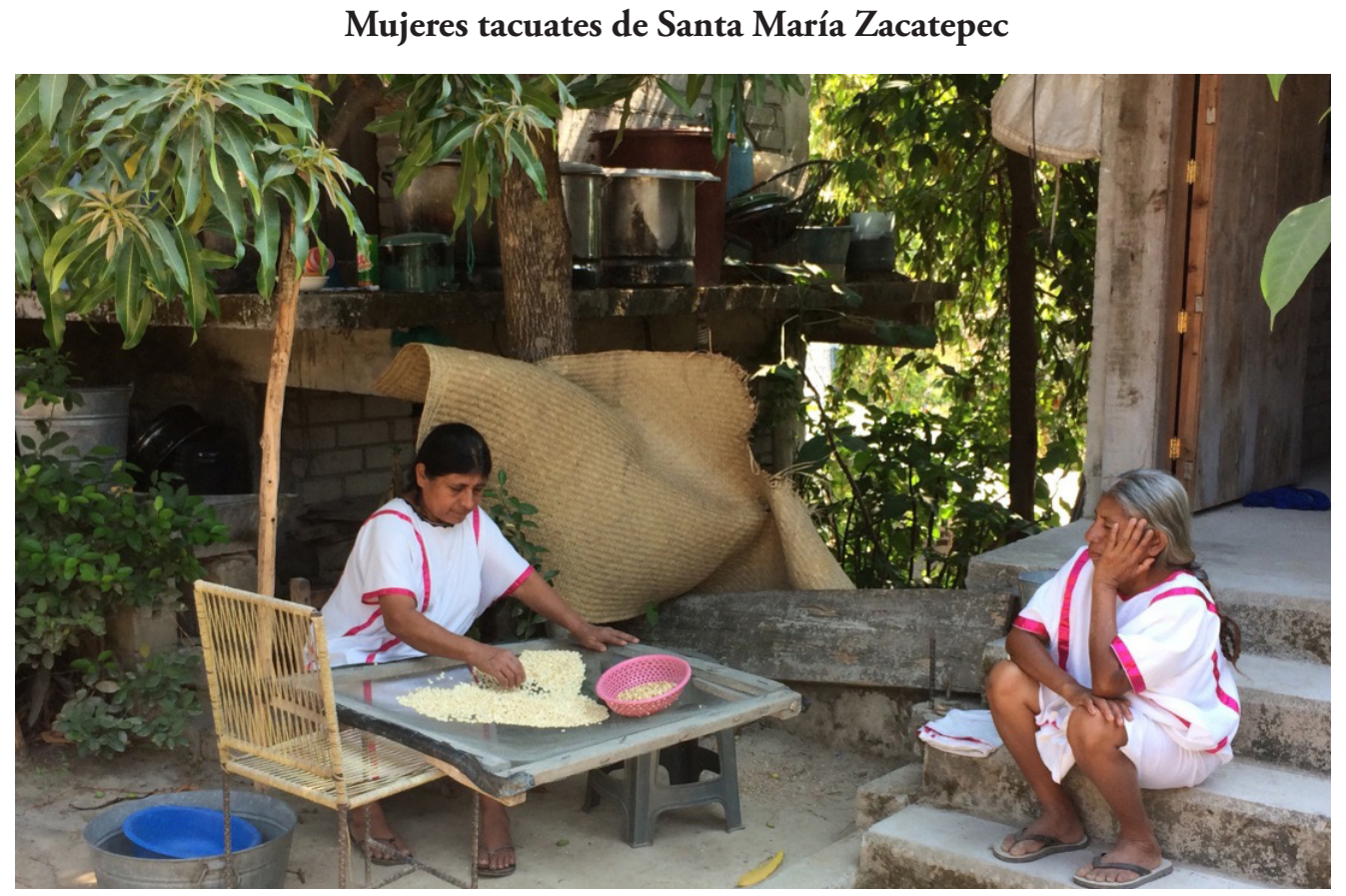

Fuente: María del Carmen Castillo Cisneros, 2016.

EntreDiversidades. Revista de Ciencias Sociales y Humanidades, vol. 8, núm. 1 (16), enero-junio 2021. Páginas: 164 - 185 ISSN-e: 2007-7610. https://doi.org/10.31644/ED.V8.N1.2021.A07 


\section{Sobremesa}

Es evidente que el video referido está hecho para un público extranjero, que, atraído por aquella idea colorida de un México surreal propuesta, no resistirá quedarse al margen de la experiencia que Olvera propone. Por tanto, pareciera que el resultado mercantilista prima sobre el conocimiento del mole y su complejidad como alimento de culturas vivas. Sin embargo, se reduce a ser una carta de invitación para aquellos que después de verlo solo quieran probar mole, experimentar color, danzas y comprar máscaras que recuerdan orígenes paganos y, por tanto, "primitivos". Refuerza la idea de que a Oaxaca se viene a comer, a tomar mezcal y a vivir, por un par de días, ese México ahora tan "tuneado" que no necesariamente corresponde con la realidad, pero que sabemos es un buen gancho y encanta.

Es tiempo de ser críticos ante ello, de cuestionarnos sobre otras formas posibles de presentar lo nuestro con sus folclorismos o también en ausencia de ellos. Por otro lado, no quiero omitir que tuve la oportunidad de conocer a Bruno ${ }^{13}$ y a Jorge, dos jóvenes que trabajaron en Pujol recientemente. Uno lisboeta y otro oaxaqueño. Mediante entrevistas separadas, pude acercarme a algo que, desde la óptica del video referido, francamente, no imaginaba sucedía dentro de las cocinas de Olvera. Menciones de trabajo en equipo, compromiso, de respeto por cada ingrediente y sus productores; de pago justo, de oportunidades y buen trato. La cocina de Pujol es solidaria, amigable y preocupada por el bienestar y aprendizaje de cada una de las partes. Una cocina desde la cual ambos aprendieron a amar lo propio y que sembró en cada uno el interés en regresar a la tierra que los vio nacer para arrancar proyectos de cocina tradicional.

Si todo ello rodea la cocina de Olvera, me pregunto, ¿qué fue entonces lo que lo motivó a presentar lo presentado? A veces es mejor dejar que las cosas, desde su praxis, hablen por sí solas. $\mathrm{O}$, ¿acaso tenemos miedo de mostrarnos tal cual somos sin necesidad de exacerbar los símbolos de una mexicanidad grotesca y exóticamente exagerada basada en discursos tradicionales como si ello fuera el único asidero que permite legitimar una identidad? Cuando pienso esto, el cuestionamiento me rebota al contexto de mi propio quehacer antropológico heredero de una antropología colonialista fincada en la necesidad de lo original, auténtico y ancestral.

El mole, al igual que Oaxaca, al igual que México y al igual que todas las cocinas que van por el mundo creando sellos de identidad a través de recurrir a "los patrimonios", forma parte de un cúmulo de relaciones y contextos que, como todo lo que pertenece a la cultura, tiene un carácter dinámico que se acopla a nuevos tiempos. Tiempos en que "la alimentación tradicional ha dejado de estar en las cocinas de las casas para mudarse a los restaurantes” (Contreras en Ortí, 2014). Desde mi punto de vista, no es necesario recurrir a aquellos esencialismos que siempre fascinan, cuando la realidad sin maquillajes también es capaz de proporcionar deslumbrantes instantáneas donde el mole, por mencionar un platillo, jamás perderá su atractivo. No hace falta extremar lo exótico para enaltecer la historia. En este sentido, como mencionan Grasseni y Paxson (2015), la reinvención no crea cosas nuevas, sui generis; más bien, da nueva forma y significado a las sustancias alimenticias, sentidos y prácticas que pueden parecer reflexivamente familiares para algunos, mientras curiosamente exóticas para los demás.

\footnotetext{
${ }^{13}$ Bruno Couto fue entrevistado en julio de 2018 en Lisboa.
}

EntreDiversidades. Revista de Ciencias Sociales y Humanidades, vol. 8, núm. 1 (16), enero-junio 2021. Páginas: 164 - 185 ISSN-e: 2007-7610. https://doi.org/10.31644/ED.V8.N1.2021.A07 
En estos tiempos, en que el patrimonio alimentario se ha convertido en espectáculo (Contreras y Ribas, 2014), valdría la pena hacer un alto, pues ya lo decía Lévi-Strauss (1992), pionero en investigar las relaciones entre comida y cultura, "si es bueno para comer, entonces es bueno para pensar". En el camino hacia ello, prima la utilización de una ética relacional frente al manejo de contenidos culturales que, como mencioné a lo largo de este texto, tienen memorias y dueños y, por tanto, repercusiones y afectaciones sociales.

\section{Bibliografía citada}

Acosta Márquez, Eliana (2018). "Cuando el sentido acontece. Una mirada metodológica sobre la narrativa y la cosmología desde una comunidad nahua de la Sierra Norte de Puebla”. Diario de campo, cuarta época año 2 (4), pp. 113-125. También disponible en: https:// mediateca.inah.gob.mx/repositorio/islandora/object/articulo: 17107

Barros, Cristina (2005). "Los moles. Aportaciones prehispánicas". En: Patrimonio Cultural y turismo. Cuadernos. El mole en la ruta de los dioses. $6^{\circ}$ Congreso sobre Patrimonio Gastronómico y Turismo Cultural, Puebla (2004). México, D. F., México: Consejo Nacional para la Cultura y las Artes, pp.19-27. También disponible en: https://patrimonioculturalyturismo. cultura.gob.mx/publi/Cuadernos 19 num/cuaderno12.pdf

Boege, Eckart (2017). "El patrimonio biocultural y los derechos de los pueblos indígenas, comunidades locales y equiparables". Diario de campo, cuarta época (1), pp. 39-69. También disponible en: https://mediateca.inah.gob.mx/repositorio/islandora/object/ articulo: 15861

Castillo Cisneros, María del Carmen (2013). "Culebras de maíz: los xatsy del depósito ritual ayuujk en Oaxaca”. Les Cahiers ALHIM, núm. 25. DOI: https://doi.org/10.4000/ alhim.4455 (Consultado el 20 de septiembre de 2019).

Castillo Cisneros, María del Carmen (2014). Kojpk Pääjtïn: El encuentro con la raíz. Una etnografía ayuujk. Tesis inédita para obtener el grado de Doctorado en Estudios Avanzados en Antropología Social, Departamento de Antropología e Historia de América, Universidad de Barcelona.

Contreras, Jesús y Ribas, Joan (2014). "Sobre la construcció social del patrimoni alimentari”. Revista d'Etnologia de Catalunya [en línea], núm. 39, pp. 84-94. Disponible en: https:// www.raco.cat/index.php/RevistaEtnologia/article/view/279980/367674 (Consultado el 7 de octubre de 2019).

Douglas, Mary (1972). “Deciphering a Meal”. Daedalus, 101 (1), pp. 61-81. También disponible en: https://www.jstor.org/stable/20024058?seq=1

EntreDiversidades. Revista de Ciencias Sociales y Humanidades, vol. 8, núm. 1 (16), enero-junio 2021. Páginas: 164 - 185 ISSN-e: 2007-7610. https://doi.org/10.31644/ED.V8.N1.2021.A07 
Escobar Rivera, Juan Carlos (2014). "Cocinando el cuerpo: La cocina tradicional como forma de resistencia”. En: Memoria Académica. VIII Jornadas de Sociología de la Universidad Nacional de La PLata, 3 al 5 de diciembre de 2014. Ensenada, Argentina: Bibhuma, biblioteca de la Facultad de Humanidades y Ciencias de la Educación, Universidad Nacional de La Plata. Disponible en: http://www.memoria.fahce.unlp.edu.ar/trab eventos/ev.4708/ev.4708.pdf (Consultado el 13 de septiembre de 2019).

Fischler, Claude (1995). El (h) omnivoro. El gusto, la cocina y el cuerpo. Barcelona: Anagrama.

Fischler, Claude (2010). "Gastro-nomía y gastro-anomía. Sabiduría del cuerpo y crisis biocultural de la alimentación moderna”. Gazeta de Antropología, 26 (1). También disponible en: https://digibug.ugr.es/handle/10481/6789

Frigolé, Joan (2008). "Processos de patrimonialització, ideología i poder. Un exemple de l'Alt Urgell”. IBIX, núm. 5, pp. 47-59. También disponible en: https://www.raco.cat/index. php/AnnalsCER/article/view/225075/306289

Grassseni, Cristina y Heather, Paxson (2015). Introducing a Special Issue on the Reinvention of Food: Connections and Mediations. Gastronomica. The journal of critical food studies, 14 (4), pp. 1-6. Disponible en: https://gastronomica.org/2015/02/04/introducing-specialissue-reinvention-food// (Consultado el 17 de septiembre de 2019).

Hernández Albarrán, Lilia (2018). "De la cultura alimentaria, cocina tradicional y gastronomía mexicana: algunas reflexiones”. Diario de campo, cuarta época (4), pp. 15-27. También disponible en: https://mediateca.inah.gob.mx/repositorio/islandora/object/ articulo\%3A17100

Hierba Dulce (2019) Nosotras [en línea] Disponible en: https://www.hierba-dulce.com/ (Consultado el 20 de diciembre de 2019).

Hobsbawm, Eric (1989) L’invent de la tradició. Barcelona: Eumo.

Lévi-Strauss, Claude (1992 [1958]). Antropología estructural. Barcelona: Paidós.

Manifiesto estridendista (1923). Disponible en: https://icaadocs.mfah.org/s/en/ item $/ 737784 \# \mathrm{c}=\& \mathrm{~m}=\& \mathrm{~s}=\& \mathrm{cv}=\& \mathrm{xywh}=-1673 \% 2 \mathrm{C} 0 \% 2 \mathrm{C} 5895 \% 2 \mathrm{C} 3299$ (Consultado el 10 de septiembre de 2019).

Merlo, Eduardo (2017). "Chilmolli; el abuelo del mole". Artes de México, El chile. Fruto ancestral, núm. 126, pp. 31-39.

Mintz, Sidney (2003). Sabor a comida, sabor a libertad. Incursiones en la comida, la cultura y el pasado. México: Consejo Nacional para la Cultura y las Artes - Centro de Investigaciones y Estudios Superiores en Antropología Social.

Nowness (2017). What Makes Mole Sauce? [video]. Disponible en: https://www.youtube.com/ watch?v=Q4WDmXh6CT0 (Consultado el 13 de diciembre de 2017).

Ortí, Antonio (2014). Jesús Contreras explica mientras mastica un canelón tibio de centollo toda la antropología que se esconde tras la alimentación. [en línea] Comer o no comer. Disponible en: https://comeronocomer.es/entrevistas-mitologicas/jesus-contreras-explica-mientrasmastica-un-canelon-tibio-de-centollo-toda (Consultado el 7 de octubre de 2019).

Pilcher, Jeffrey (2001) ;Vivan los tamales! México: Consejo Nacional para la Cultura y las Artes. Prats, Llorenç (1997). Antropología y patrimonio. Barcelona: Ariel.

EntreDiversidades. Revista de Ciencias Sociales y Humanidades, vol. 8, núm. 1 (16), enero-junio 2021. Páginas: 164 - 185 ISSN-e: 2007-7610. https://doi.org/10.31644/ED.V8.N1.2021.A07 
Pujol (2019). Nosotros. [en línea] Disponible en: http://pujol.com.mx/ (Consultado el 20 de diciembre de 2019).

Taibo, Benito (2005). "El libro de todos los moles". Patrimonio Culturaly turismo. Cuadernos. El mole en la ruta de los dioses. México: Consejo Nacional para la Cultura y las Artes, pp. 117-120.

Villoro, Juan (2011). "Metafísica para glotones". Letras Libres [en línea]. Disponible en: https:// www.letraslibres.com/mexico/metafisica-glotones (Consultado el 15 de septiembre de 2019).

Villoro, Juan (2015). "Para comerte mejor: el águila y la serpiente. Prólogo". México de adentro hacia afuera. Enrique Olvera. Nueva York, Estados Unidos de América: Phaidon, pp. 9-15. 